\title{
Clinical history and classic palmar hyperhidrosis
}

\author{
Fritz Baumgartner
}

Published online: 29 May 2009

(C) Springer-Verlag 2009

Dr. Keller [5] and coauthors are to be congratulated, not for a novel finding per se, but for laying the groundwork for future truly groundbreaking work in the understanding and treatment of hyperhidrosis. Their rigorous study scientifically and objectively validates what has long been known: that one can predict by history alone which patients truly have classic palmar hyperhidrosis. Their questionnaire is a reliable, selfadministered instrument that can accurately verify which patients have the disorder, so that remote sampling of these patients can be done for genetic and epidemiologic study. It is important here to add the caveat that classic palmar hyperhidrosis is a special subset within the broad and indiscriminate diagnosis of "hyperhidrosis." This, in its typical form, is more accurately described as palmoplantar hyperhidrosis [1], since the soles of the feet are, in the overwhelming majority of instances, involved in pathologically excessive sweating as well; severe underarm sweating may or may not be coexistent in this typical form and is not a necessary component for diagnosing the condition. The vast majority of the palmoplantar patients also acknowledge a bimodal onset of the disorder (in early childhood or at puberty) and the observation that ordinary hand lotion applied to the hands is an extremely sensitive provocative agent. These clinical observations, establishing the clinical uniqueness of the disorder, have in the past often been neglected by recommendations in the medical literature and insurance carriers, to the detriment of

F. Baumgartner ( $\square)$

Center for the Cure of Hyperhidrosis,

Fountain Valley, CA, USA

e-mail: f.baumgartner@earthlink.net

F. Baumgartner

Harbor-UCLA Medical Center,

UCLA School of Medicine, Los Angeles, USA patients truly suffering from classic disabling palmoplantar hyperhidrosis. That modern surgical sympathectomy has overwhelming advantages to standard medical management in treating classic disabling hand sweating in the classic palmoplantar group cannot be denied, and the former can be considered a first-line treatment $[2,6]$. The key to treatment efficacy and low incidence of problematic compensatory sweating is proper patient selection. Facial and axillary hyperhidrosis are completely different disease entities from palmoplantar sweating and cannot be lumped into the same clinical and treatment categories.

This, of course, is not to say that future novel treatments of palmoplantar hyperhidrosis cannot improve on the currently good results of thoracoscopic sympathectomy, since despite our best efforts, the incidence of problematic compensatory sweating cannot be eliminated, and plantar sweating is often not satisfactorily corrected. Keller et al. correctly surmise that a more fundamental genetic and physiologic understanding of the basis of this disorder is necessary for truly groundbreaking treatments to emerge. Although preliminary studies point to chromosomes 14 and $5[3,4]$, much more work needs to be done, and the excellent contribution of Keller et al. is a major step in this direction. And, not insignificantly, old-fashioned physicians can also take solace in the affirmation that expensive testing is not necessary in establishing a diagnosis and that the patient's history, as we were taught in medical school, remains the gold-standard in the diagnosis of human disease.

\section{References}

1. Baumgartner FJ (2008) Surgical approaches and techniques in the management of severe hyperhidrosis. Thorac Surg Clin 18:167181 
2. Baumgartner FJ, Bertin S, Konecny J (2009) Superiority of thoracoscopic sympathectomy over medical management for the palmoplantar subset of severe hyperhidrosis. Ann Vasc Surg 23:1-7

3. Cantor-Chiul RM, Chandra F, Dorrani N, Swatling C, Glaser D, Ahn S (2006) Evidence of a hyperhidrosis risk gene at 5q11.2. Abstract \#1706, Presented at the annual meeting of Am Soc Human Genetics, 10 October 2006, New Orleans, Louisiana. Available from http://www.ashg.org/genetics/ashg/annmeet/2006

4. Higashimoto I, Yoshiura K, Hirakawa N, Higashimoto K, Soejima H, Totoki T, Mukai T, Niikawa N (2006) Primary palmar hyperhidrosis locus maps to 14q11.2-q13. Am J Med Genet 140A:567-572
5. Keller SM, Bello R, Vibert B, Swergold G, Burk R (2009) Diagnosis of palmar hyperhidrosis via questionnaire without physical examination. Clin Auton Res. doi:10.1007/s10286-0090006-5

6. Reisfeld R, Berliner KI (2008) Evidence based review of the nonsurgical management of hyperhidrosis. Thorac Surg Clin 18:157-166 